\title{
Chapter 7 \\ From Content Knowledge to Competencies and Exams to Exit Profiles: Education Reform in Zimbabwe
}

\author{
Djénéba Gory, Jayanti Bhatia, and Venkatesh Reddy Mallapu Reddy
}

\subsection{Introduction}

The post-colonial era of the 1980s was marked with significant progress in Zimbabwe's education reform and policies. From making public schooling available for all to working on teacher training, the country seemed to be on the right track and was setting an example for other African nations. These remarkable efforts were praised by multilateral organizations such as UNESCO and UNICEF (UNICEF News Note, 2009). However, by the early 2000s amidst the political, economic, and financial crisis of hyperinflation, the tides turned in the opposite direction. The education system failed to keep pace and Zimbabwean students started struggling to meet the demands of the labor market. The political cadre in Zimbabwe saw the need for an ambitious education reform that could serve all children, and at the same time, held the potential to pull the country out of the turmoil and thereby pave Zimbabwe's way forward to economic development.

With this in mind, the government of Zimbabwe started working on enhancing the quality of education by shifting from content knowledge to competency oriented curriculum. The Ministry of Primary and Secondary Education (MoPSE) started developing the Zimbabwe Curriculum Framework (ZCF) in 2014. It was developed and finalized in 2015 and its phased implementation commenced in 2017. The framework provides a comprehensive plan (2015-22) for a rapid and sustainable transformation of Zimbabwe's education system. While Kenya's reform (Chap. 6) was ambitious in introducing both the curriculum and structural changes, Zimbabwe's reform focused mainly on curriculum. Everything else moved around

D. Gory

Harvard Kennedy School, Cambridge, MA, USA

J. Bhatia $(\bowtie) \cdot$ V. R. M. Reddy

International Education Policy, Harvard Graduate School of Education,

Cambridge, MA, USA 
the curriculum and was an attempt of a systemic alignment to help implement the new curriculum. Additionally, analyzing the reform from Reimers' five frames theory on educational change (Reimers, 2020), we found that Zimbabwe's education reform was implemented addressing elements of each of the five perspectives. We argue, however, that when these perspectives are not adequately addressed, they present critical challenges in the success of the envisioned reform.

As of early 2020, the reform implementation is in its last leg and this chapter examines the progress to date. It begins with an overview of the country's education system and conditions that shaped the reform, followed by a more detailed description of the reform, its theory of change, and implementation timeline. It then analyzes the reform stages through the five perspectives of educational change (Reimers, 2020). The chapter concludes by presenting the results and challenges at the time of writing. All information unless otherwise cited has been obtained either from the Ministry of Primary and Secondary Education (MoPSE) or through several interviews and focus groups conducted during in-country research in January 2020. The references section provides more details under "In-Country Research" (2020).

a. Interviews were conducted with 52 officials from 6 departments of MoPSE Curriculum Development and Technical Services Department; Human Resources and Discipline Department; Primary, Secondary and Non-Formal Education Department; Procurement Management and Business Development Unit; Centre of Education, Research, Innovation and Development; Finance Department.

b. Zimbabwe School Examinations Council (ZIMSEC); Zimbabwe Early Learning Assessments Team (ZELA); South East African Council for Monitoring Educational Quality (SEACMEQ).

c. Education Coordination Group partners such as World Bank, UNICEF, UNESCO, CSOs.

d. Textbook Publishers.

e. Provincial Education Directors, District School Inspectors, National Association of Primary School Heads and, National Association of Secondary School Heads.

f. Additionally, we held individual and focus group interviews in 7 schools in 3 out of 9 provinces in Zimbabwe where we interviewed 32 School Heads, 70 Teachers, 36 Parents and 38 Students.

\subsection{Country Context}

\subsubsection{Zimbabwe's Education System}

According to UNESCO (2017) figures, Zimbabwe has a young population, with $42 \%$ under the age of 14 (6.1 million of a total 14.4 million). Figure 7.1 shows the school-age population by level of education. Figure 7.2 further shows the widespread distribution of school types across primary $(\mathrm{P})$ and secondary $(\mathrm{S})$ grades. The vast majority of schools are rural and government-owned. In terms of literacy rate, 


\begin{tabular}{|l|l|l|l|l|}
\multicolumn{1}{|c|}{ LEVEL } & $\begin{array}{c}\text { AGE GROUP } \\
\text { (YEARS) }\end{array}$ & $\begin{array}{c}\text { TOTAL } \\
\text { POPULATION }\end{array}$ & $\begin{array}{c}\text { ENROLLED } \\
\text { POPULATION }\end{array}$ & $\begin{array}{c}\text { PROPORTION } \\
\text { ENROLLED }\end{array}$ \\
\hline Preschool/pre-primary (ECD A-ECD B) & $4-5$ & 984,659 & 623,981 & $63 \%$ \\
\hline Primary (P1-P7) & $6-12$ & $3,028,319$ & $2,676,485$ & $88 \%$ \\
\hline Secondary (S1-S6) & $13-18$ & $2,146,723$ & $1,075,325$ & $50 \%$ \\
\hline Total: & - & $\mathbf{6 , 1 5 9 , 7 0 1}$ & $\mathbf{4 , 3 7 5 , 7 9 1}$ & $\mathbf{7 1 \%}$ \\
\hline
\end{tabular}

Fig. 7.1 Zimbabwe's primary and secondary school enrolment (2017)

Source: UNESCO Institute of Statistics (http://uis.unesco.org/en/country/zw) Annual Statistical Digest (EMIS, 2017)

\begin{tabular}{|l|l|l|l|l|}
\hline & \multicolumn{1}{|c|}{ PRIMARY (N) } & \multicolumn{1}{|c|}{ PRIMARY (\%) } & \multicolumn{1}{|c|}{ SECONDARY (N) } & SECONDARY (\%) \\
\hline Urban (P1/S1) & 234 & $4 \%$ & 205 & $7 \%$ \\
\hline Semi-urban (P2/S2) & 486 & $8 \%$ & 336 & $12 \%$ \\
\hline Rural (P3/S3) & 5,403 & $88 \%$ & 2,289 & $81 \%$ \\
\hline Registered & 5,107 & $83 \%$ & 1,991 & $70 \%$ \\
\hline Satellite & 1,016 & $17 \%$ & 839 & $30 \%$ \\
\hline Government-owned & 5,260 & $86 \%$ & 2141 & $76 \%$ \\
\hline Non-government-owned & 863 & $14 \%$ & 689 & $24 \%$ \\
\hline Total schools & 6,123 & - & 2,830 & - \\
\hline
\end{tabular}

Fig. 7.2 Zimbabwe's school categories by demography, registry, and funding management Source: Education Sector Analysis (2015)

which Zimbabwe defines as completion of at least Grade 3 for the population aged 15 and above, the country stands at $88.69 \%$ compared to $63.49 \%$ for Sub-Saharan Africa according to a World Bank report (World Bank, 2014). This is one of the highest adult literacy rates in Africa. According to the 2015 Zimbabwe Demographic and Health Survey data $73 \%$ of women and $77 \%$ of men aged $15-49$ have also attended or completed secondary school or higher (Demographic and Health Survey, 2016).

However, despite the high literacy rate, Zimbabwe's education system was not adequately preparing students for life and labor market demands. Like many other former colonies, the system was designed based on the British system. Zimbabwe tried to add an additional year by addition of Grade 13 vis-à-vis Form 6, so as to increase the probability of all students closing their learning gaps because of an added school year. As depicted in Fig. 7.3, Zimbabwe's school system now comprises 4 years of infant education (including 2 years of early childhood education (ECE) and 2 years of formal primary), 5 years of junior education (ending in Grade 7 examinations), and 6 years of secondary school, with three sets of state exams at Grades 7, 11 (O Level) and 13 (A Level). Students progress automatically from one grade to the next until Grade 7. During the first half of Grade 3, a sample of students also take the Zimbabwe Early Learning Assessment (ZELA) that examines their Grade 2 competencies and generates evidence to help improve learning. All national examinations are set by the Zimbabwe School Examinations Council (ZIMSEC). 


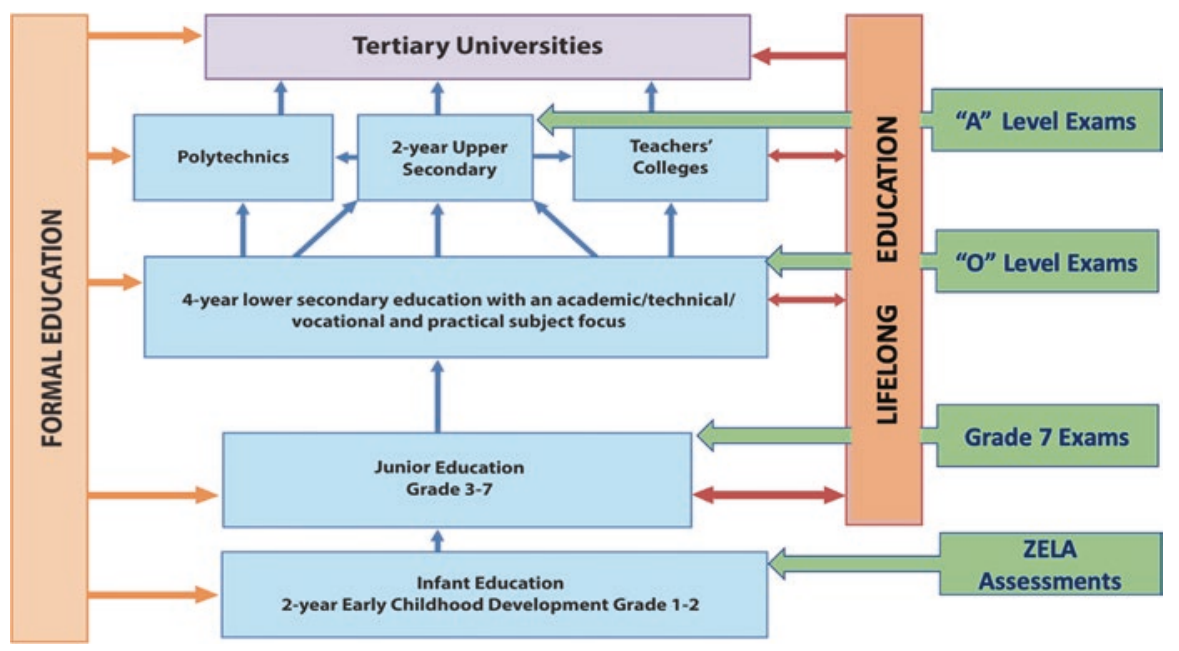

Fig. 7.3 Zimbabwe's education system

Source: Education Sector Strategic Plan (2016-20). Modified to highlight the exam and assessment levels

\subsubsection{Conditions that Shaped the Reform}

While the data above gives us a snapshot in time, it is also essential to know the numerous conditions that directly or indirectly shaped the reform. A country's education system does not sit in a vacuum but is rather situated within a complex web of economic, political, and financial spheres among others. Zimbabwe has been experiencing volatile conditions since over a decade. First, numerous ordeals, including cash shortages, fiscal deficits, unsustainable external debt arrears, unemployment, poverty and poor provision of social services, among other factors characterize the economic state of Zimbabwe (Universalia, 2019, p. 28). Second, in 2008 , the country underwent a serious economic shock that was characterized by hyperinflation, collapse of living standards, and loss of international confidence (Universalia, 2019, p. 28). The hyperinflation has been continuing to date and the country suffered a currency crisis in 2018-19. ${ }^{1}$ Third, on the political front, the 37-year president, Robert Mugabe, resigned amid threats of impeachment charges in 2017. All this halted and arguably even reversed the educational progress that the country had made in the post-colonial period between 1980s and 2000s.

These conditions additionally posed a barrier to some of the earlier attempts to address the educational challenges of Zimbabwe and thus further aggravated the gaps and challenges. One such significant attempt was made in 1999, by the then

\footnotetext{
${ }^{1}$ Inflation rates were at peak in mid-2000s, and while the World Bank does not have data for this peak period, Zimbabwe's central bank reported it at just under 80 billion \% in mid-November 2008. Post this peak, the central bank stopped reporting monthly statistics.
} 
president of the republic of Zimbabwe, Robert Mugabe. He assigned the Commission of Inquiry into Education and Training (CIET) to look into the structure and content of education for diagnosing the problems that were affecting the system because of phenomenal expansion. Following nation-wide consultations and international study trips, the team produced an invaluable report called the Nziramasanga Report. The country, however, could not act much on this for almost 15 years, because of fiscal constraints.

Like any other government or organization, faced with a similar challenge, the government of Zimbabwe had two options to overcome it during the 2010s. First was to act with urgency and opt for a full-fledged systemic overhaul in one go and second was to opt for a Singapore-like more gradual approach of ensuring implementation quality in one component of the reform before proceeding to the next. Zimbabwe chose the former i.e., a full-fledged reform from 2015 to 2022 that was phased out by grade-level to allow logistical and operational efficiency. However, planning is an oxymoron in such volatile conditions, especially amidst the financial crisis when it is hard to estimate what resources will be available. But does this mean that countries should put education in the backburner during such a crisis? Zimbabwe chose not to and worked hard to bring in a socio-economic transformation vision called Zimbabwe Agenda for Sustainable Socio-Economic Transformation (ZimASSET) which was a medium term 5-year plan for the country's economic reform and all-round growth (ZimASSET, 2015). Recognizing that the 15 years following the 1999 CIET Report had brought in various changes on the national landscape along with a global movement of the Information and Communication Technology (ICT), the blueprint underscored the need for a curriculum review albeit using CIET as a springboard. The goal was to reform the curriculum to develop students who would be prepared to navigate the evolving demands of the twenty-first-century.

A nationwide curriculum review process thus began in 2013 and was formally launched in October 2014. This process involved a nationwide consultation and culminated in the creation of the Narrative Report 2014-2015. This was followed by the approval of the new curriculum in 2015 and led to the creation of the Zimbabwe Curriculum Framework (ZCF) for Primary and Secondary Education (2015-22). During implementation, when finances went out of control, rather than abandoning the reform, the government chose to adjust the plan and continued moving forward, thereby ensuring continued progress even if it came at the cost of reduced quality and accountability in a few places.

Additionally, it is worth noting that the Global Partnership for Education (GPE) played a key role in supporting Zimbabwe's efforts of curriculum reform. GPE not only brought in the international aid to support all the reforms, but also helped shape the reform agenda through the Education Coordination Group (ECG) ${ }^{2}$ which

\footnotetext{
${ }^{2}$ The national forum for multi-party stakeholder engagement in the Education Sector Strategic Plan (ESSP), consisting of the Ministry (MoPSE), Ministry of Finance and Economic Development (MoFED), Ministry of Higher and Tertiary Education, Science and Technology Development (MoHTESTD), World Bank (WB), UNICEF, UNESCO, Global Partnership for Education (GPE),
} 
consists of International donor partners. While the reforms were planned and implemented primarily by the government and its associated ministry (MoPSE), the development of the reform itself was influenced by the ideas and technical expertise from GPE and other partners such as UNESCO, UNICEF, DFiD and ACER (ESSP, 2016). The focus on twenty-first-century skills, competencies, and Science, Technology, Engineering, Arts and Mathematics (STEAM) evolved from the global agenda ${ }^{3}$ across the world for re-aligning education systems to twenty-first-century skill based curriculum and STEM education. This ultimately influenced the redesign of the curriculum and the development of learning areas and syllabus.

\subsection{The Reform and its Theory of Change}

As discussed thus far, the recommendations of the Narrative Report along with the ones from the earlier Nziramasanga Report, formed the basis for the Zimbabwe Curriculum Framework (ZCF) for Primary and Secondary Education (2015-2022). The Ministry of Primary and Secondary Education (MoPSE) recognized the need to shift the emphasis from content knowledge mastery to higher-order thinking skills and competencies. Several new learning areas were added to drive this shift. According to the ZCF document the goals of the reform were to (a) promote and cherish the Zimbabwean identity, (b) prepare learners for life and work in a largely agro-based economy and an increasingly globalized and competitive environment, (c) foster life-long learning in line with the opportunities and challenges of the knowledge society, (d) prepare learners for participatory citizenship, peace and sustainable development, and (e) prepare and orient learners for participation, leadership and voluntary service.

The theory of change, in particular, was that, if the curriculum is entirely overhauled from an outdated focus on knowledge transmission to focusing on the development of twenty-first-century skills and competencies, and if it is scaffolded by the provision of the updated syllabus and learning materials along with trained teachers to deliver the new curriculum, then the classroom experience and learning outcomes would advance for all students in the short-term. In the medium-term, students would achieve the desired exit profiles as defined in the new ZCF, and in the longterm, they would ultimately be able to meet the economy and labor market demands. Students would thus be better equipped to contribute to the country's socio-economic transformation.

The new curriculum supports students to build a strong scientific and technological mindset and to prepare them for the evolving needs of the twenty-first-century.

DFiD, and Civil Society Organizations (CSOs such as CAMFED and ECOZI) were named part of the Education Coordination Group (ECG).

${ }^{3}$ Finland, Singapore, Ghana had already implemented a twenty-first-century Competency-based Curriculum and began performing well on PISA scores which influenced the adoption of such curriculums across the world and Countries started redesigning so as to catch up to them. 


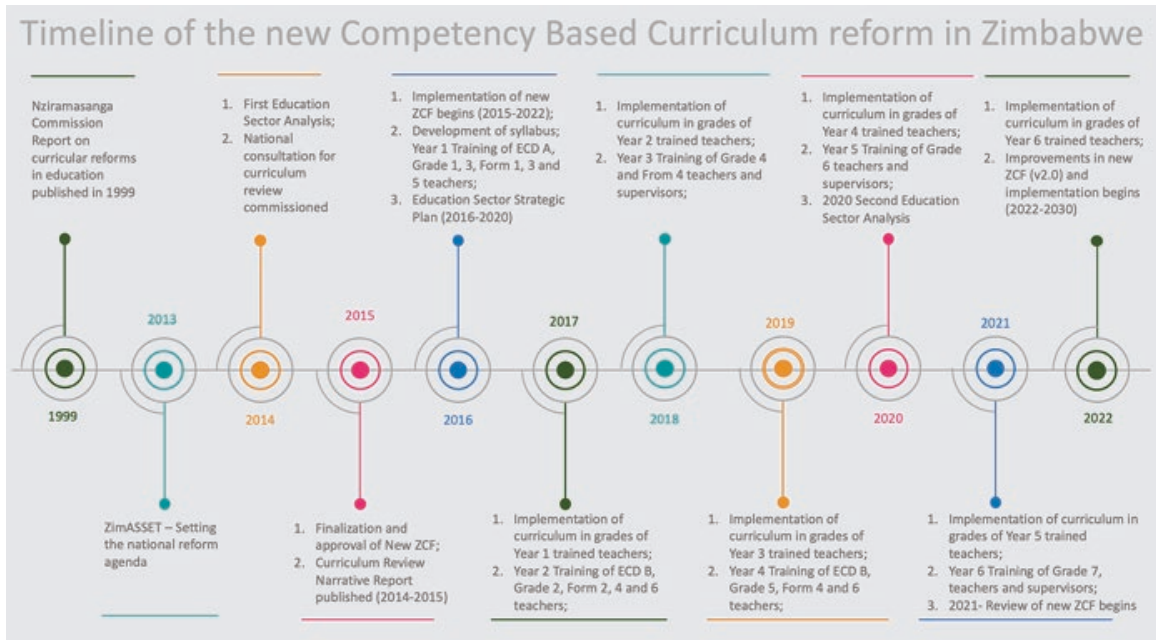

Fig. 7.4 Timeline of the new competency based curriculum reform in Zimbabwe Source: Created by the authors (2020)

It has elements of adoption of a philosophical approach Ubuntu/Unhu/Vumunhu (i.e., self-respect and respect for others) along with an emphasis on STEAM and Information and Communication Technology (ICT). Additionally, humanities, agriculture, technical/vocational business, and commercial fields among other crosscutting themes such as civic, environment, finance, human rights, health, HIV/ AIDS, climate change, and disaster risk reduction encompass a holistic education. The introduction of life-skills orientation programme (LOP), continuous assessments, and learner exit profiles are some of the other key features of the new framework.

As illustrated in Fig. 7.4 the implementation of the new curriculum started in 2017 with the plan to be phased in until 2022 as the first batch progresses from one grade to the next. To ensure a successful roll-out, MoPSE developed school packages in the form of CDs which contained the new curriculum framework document, the newly developed syllabi, and the continuous assessment tasks to be used by the teachers. Our field visits established that while few schools received these packages, others were still awaiting the materials.

Further on, as re-emphasized throughout the book, five main perspectives can be deployed to design and implement educational reforms: cultural, psychological, professional, institutional, and political (Reimers, 2020). We found that while certain perspectives outweighed others, all these collectively framed Zimbabwe's curriculum reform. The reform was cultural in terms of (a) government's attempt to incorporate voices of various stakeholders throughout the planning and implementation process, and (b) parents' understanding of the importance of education that drove their financial contribution even though they could hardly afford schooling; 
psychological as the curriculum was developed by understanding the learner exit profiles and competencies by grade and learning area; professional as it redesigned the roles for teachers and school administrators to align them to the new curriculum goals and second as it planned for professional development to ensure successful curriculum delivery; institutional as it accounted for social and institutional structures to support teaching and learning, stakeholder interactions, and monitoring of quality of educational delivery and implementation; and finally political as it was driven by the political class who (a) understood that education affects the chances of every student to succeed in life and contribute to the country's economy, and (b) had the courage to champion the reforms and stick with it amidst the volatile conditions and change of regime.

\subsection{The Reform Stages Through Five Perspectives of Educational Change}

Zimbabwe's Education Sector Strategic Plan (ESSP), developed in 2016 with the technical and funding support of the Global Partnership for Education (GPE), aimed at providing appropriate coordination and phasing of all the required inputs for the best-in-class learning experience for all students. ESSP provides clear goals, describes the processes, and sets the agenda for regular monitoring of progress and timely adjustment if needed. ESSP laid out the following stages for educational development for the ministry to achieve its intended objectives - Development of the new competency-based curriculum (ZCF) and syllabus; professional capacity development on the interpretation and delivery of the new curriculum; preparation and availability of new learning materials such as student textbooks, teaching guides, science kits, and ICT and Science labs; and the introduction of continuous assessment. Followed by distribution of school packages to individual schools; continued professional upgrading and support for teachers; increased access to learning; right institutional architecture, great leadership, accountable management, efficient and effective resource utilization, and quality service delivery; EMIS/ TMIS (Education/Teacher Management Information Systems) data reporting and collection systems along with bringing in research perspective to monitor and improve the delivery of services; improved learning environments; and finally increased equity (Universalia, 2018). These stages are explained below in detail and are analyzed using the five perspectives of educational change (Reimers, 2020). 


\subsubsection{Political Perspective}

Reimers' political lens foregrounds how "education affects the interests of many different groups, and that those interests "may be in conflict" (Reimers, 2020). In the Zimbabwean context, the CIET commission and the blueprint for SocioEconomic Transformation of Zimbabwe (ZimASSET) were instituted by the government led by ZANU-PF and the country's former president Robert Mugabe. The government acknowledged that its economy was in a dire condition, and improving the economic conditions and bringing in growth and stability required multi-sectoral reforms. The same government was thus instrumental in starting the curricular reform in 2013, as they understood that education affects the chances of every student to succeed in life and thus positively impacts the country's economy. The government had the courage to champion the reform and stick with it amidst the volatile conditions and change of regime. The current president Emerson Mnangagwa was then the Vice-President and deputy to Robert Mugabe, and is continuing the implementation of the current reform.

On the one hand, as described in detail in Sect. 7.3.2, the ministry was able to involve the public to gather inputs on the kind of education and skills they desired for their children who would support their families and also the country's economy in the future, on the other hand, the ministry, however, did not continuously engage all stakeholders throughout the reform. Thus, not all teachers and parents were satisfied with the reform. The reform meant that teachers were not only expected to deliver the new curriculum and ensure that students had demonstrable competencies leading to exit profiles but also to assess students on these new competencies while the new assessment framework was delayed. All this was required of them using limited preparation through professional development training that focused more on the syllabus interpretation rather than delivery. Adding to the pressure were semiannual performance assessments by the headmasters and district school inspectors (DSIs). These additional teacher duties arose during an economic crisis when inflation drastically eroded the value of teacher salaries from roughly 500 USD to 30 USD per month and they could no longer afford the education of their own children. The ensuing teacher strikes thus impeded the government efforts to change education. Additionally, a majority of the parents in semi-urban and rural areas could no longer afford their children's education as the annual school fees, purchase of new textbooks and associated workbooks to takes notes for the entire year for all learning areas exceeded their earnings, forcing them to take loans to sustain the education of their children. Parents who could not achieve this had to withdraw their children from school and were subsequently upset. The reform also translated into more effort and school time for teachers as well as students, where they now had to be in schools till around 4 PM rather than the initial 1 PM.

To navigate these differences, the government implemented a series of additional sub-reforms. First, in collaboration with ECG development partners, government schemes such as BEAM (Basic Education Assistance Module) and SIG (School Improvement Grants) were launched to support school enrollments and parental 
spending. BEAM prevents households from resorting to perverse coping mechanisms such as withdrawing children from school, in response to worsening household poverty, whereas SIG provides support to over $6000 \mathrm{P} 3$ and satellite schools to provide textbooks, fee payment, and levies for vulnerable students.

Alongside this, the government initiated and finalized an amendment of the Education Act 2006, which guaranteed and protected every child's right to access and complete the basic education cycle. The same was adopted by the Constitution of Zimbabwe in 2013. This institutionalized the government's plan for having a national vision and goal for education within the Constitution, and was further used to bring in a host of associated educational policies to improve the quality of the education service across the country. Some of the many policies ranged from ICT for the education sector, school feeding, Inclusive Education, and Infant/Early Childhood policy to a policy for rationalizing School Development Committees and School Development Associations into a single entity and determining its aggregated responsibilities.

Lastly, though Zimbabwe was constricted in accessing international funding amidst sanctions from the United States ZIDERA 2001, ${ }^{4}$ European Commission and the World Bank, ${ }^{5}$ the government showed political will to implement this reform and managed to access funding from other international donors such as GPE, UNESCO, UNICEF, and DFiD through the GPE Fund and Education Development Fund (EDF). Additionally, the government managed to not only secure financial funding but also technical advisory expertise for planning and implementing the reform. It further managed to convince all the international donors and Civil Society Organizations (CSOs) to be a part of ECG, which participated in the reform design while MoPSE took the lead in planning and implementing the reform.

\subsubsection{Cultural Perspective}

The cultural perspective requires consideration of societal norms and values before undertaking the reform (Reimers, 2020). It considers what the society expects from schools or the education system in general and what the priorities are. This notion was considered throughout the planning and implementation phase in terms of incorporating voices of various stakeholders. To begin with, as part of the curriculum review process in 2013, the ministry had set up a nationwide consultation process involving technical working groups and held consultations across almost 20 platforms involving "close to a million people $(961,000)$ which included stakeholders like learners, parents, teachers, leaders in industry and commerce, farmers, church organizations, civil society, institutions of higher learning and government

\footnotetext{
${ }^{4}$ Sanctions under the Zimbabwe Democracy and Economic Recovery Act of 2001 (ZIDERA) were renewed in 2018 for one more year till 2020 under the administration of President Donald Trump. ${ }^{5}$ Because of non-payment of dues amounting to 1.8 Billion USD (WB Zimbabwe Report).
} 
ministries and departments. Furthermore, there was extensive media coverage which included advertorials, newscasts, features and interviews in all platforms" (Zimbabwe Curriculum Framework, 2015). The diverse perspectives allowed the MoPSE to ensure buy-in from relevant stakeholders and representatives of final beneficiaries, and more importantly, organizations and individuals who understood the needs of the labor market. As discussed earlier, this process culminated with the creation of the Narrative Report 2014-2015 (Narrative Report, 2014).

Additionally, the cultural perspective accounts to understand "a) how society values education and sees its relation to social purposes and values, b) how society views its teachers and learners, and c) how government involves its citizens in its reform agenda (Reimers, 2020)." In Zimbabwe, our meetings with the ministry officials and the focus group discussions with parents showed evidence that several parents saw education to be critical for their children's success in life, and for their socio-economic stability and upward mobility. This is evident when comparing government and parental spending on education. While the in-school expenditure of the ministry is close to about 950 Million Zimbabwean Dollars (ZWD), parental contribution on average is a little more at 1.2 Billion ZWD. In addition, some parents also annually donate anywhere between 150 and 500 ZWD to the school development committee (SDC) which helps sustain the improvement or management of the school infrastructure such as labs, various equipment, or other school facilities. This commitment signals a high-value and importance placed on education. It also signals that parents expect high returns for their children, expecting placement on the labor market. Overall, the total annual spending per child is anywhere between 2,400 and 6,000 dollars (ZWD) and covers school fees, uniforms, textbooks, stationery, and optional educational field trips.

Even though parents feel the economic hardships and their limited salaries do not meet the annual school expenses, many of them still sustain their children's education by taking loans as they view education as a key to their emancipation. In Zimbabwean society, parents highly value teachers and school principals. They listen to the teachers and school principals to cultivate a partnership of building their child's future through education. Some parents meet with teachers three times a year to understand their child's performance and learning gaps and to understand ways of collaboration with schools to improve learning outcomes. They build learning supports at home, based on the advice of their child's class teacher. When needed, some parents reported that they go the extra mile to provide for educational trips of their children which teachers say are critical for learning even if this means toiling hard by performing additional work to earn the required money.

\subsubsection{Psychological Perspective}

The psychological perspective requires us to consider the core questions of "what and when should students learn, how can students be supported in their learning, what and how should teachers teach, and how can teachers be supported to learn so 
that they can teach effectively (Reimers, 2020, p. 12)." To successfully implement the curriculum reform, the ministry re-imagined the learner profiles of students exiting the school system and aligned them with the demands of a twenty-first-century skills-driven workforce and economy by introducing new learning areas. The learner exit profiles are illustrated in Fig. 7.5 and draw upon from other high-performing education systems. The focus on Knowledge, Attitudes, and Skills is in line with the widely used CASEL framework of social and emotional competencies or the twenty-first-century skills (CASEL, 2017), whereas values and national identity account for the local context. These together encompass a wide range of learning areas ranging from Science, Technology, Engineering, Arts and Mathematics (STEAM), civic education, leadership, and innovation to vocational skills. Teaching of practical subjects such as Agriculture and Science along with vocational skills was envisioned to provide the necessary different pathways for students that would prepare them to become an engine of economic growth.

Based on the intended exit profiles (Fig. 7.5), the ministry then developed learning outcomes that students should have at the end of each school level ${ }^{6}$ (Infant: ECD to Grade 2; Primary: Grade 3 to Grade 7; Secondary: Form 1 to Form 4; Senior Secondary: Form 5 and 6). To meet the objectives set in the reform, two teams within the Curriculum Development and Technical Services (CTDS) department of MoPSE were in-charge of this demanding task of curriculum and syllabus development. To undertake the development of the new syllabus and ensure its alignment to the adopted curriculum, the team started by developing 104 syllabi - 8 infant, 11 junior, 41 lower, and 44 upper-secondary level. The syllabus team worked alongside the curriculum team to ensure the alignment between syllabus and curriculum. However, while the curriculum team produced only broad statements for end of school level learning outcomes, the syllabus team produced more detailed learning objectives by learning area specific subtopics at grade level to assist in classroom teaching.

Thus, although the syllabus presents considerable level of detail, the curriculum mainly shows more general objectives that are not specific to grade levels but rather to junior or senior categories in general. Though this discrepancy in granularity between the two points to a potential misalignment, the ministry has assured that the two have been aligned by its CDTS team. Our visits also highlighted that teachers primarily rely on the syllabi, so this potential misalignment does not constitute a major threat to learning outcomes.

Further, in line with the science of learning, which advocates for multiple instructional methods to accomplish varied learner outcomes, the curriculum framework advocates for varied teaching methods ranging from discovery, project-based, and problem-based to design-based for supporting student learning of twenty-firstcentury skills (Education Encyclopedia, n.d.). These are typical characteristics of a learner-centric approach with the teacher acting as a facilitator.

${ }^{6}$ The learning outcomes are outlined in Sect. 3.6 of Zimbabwe's Curriculum Framework document. 


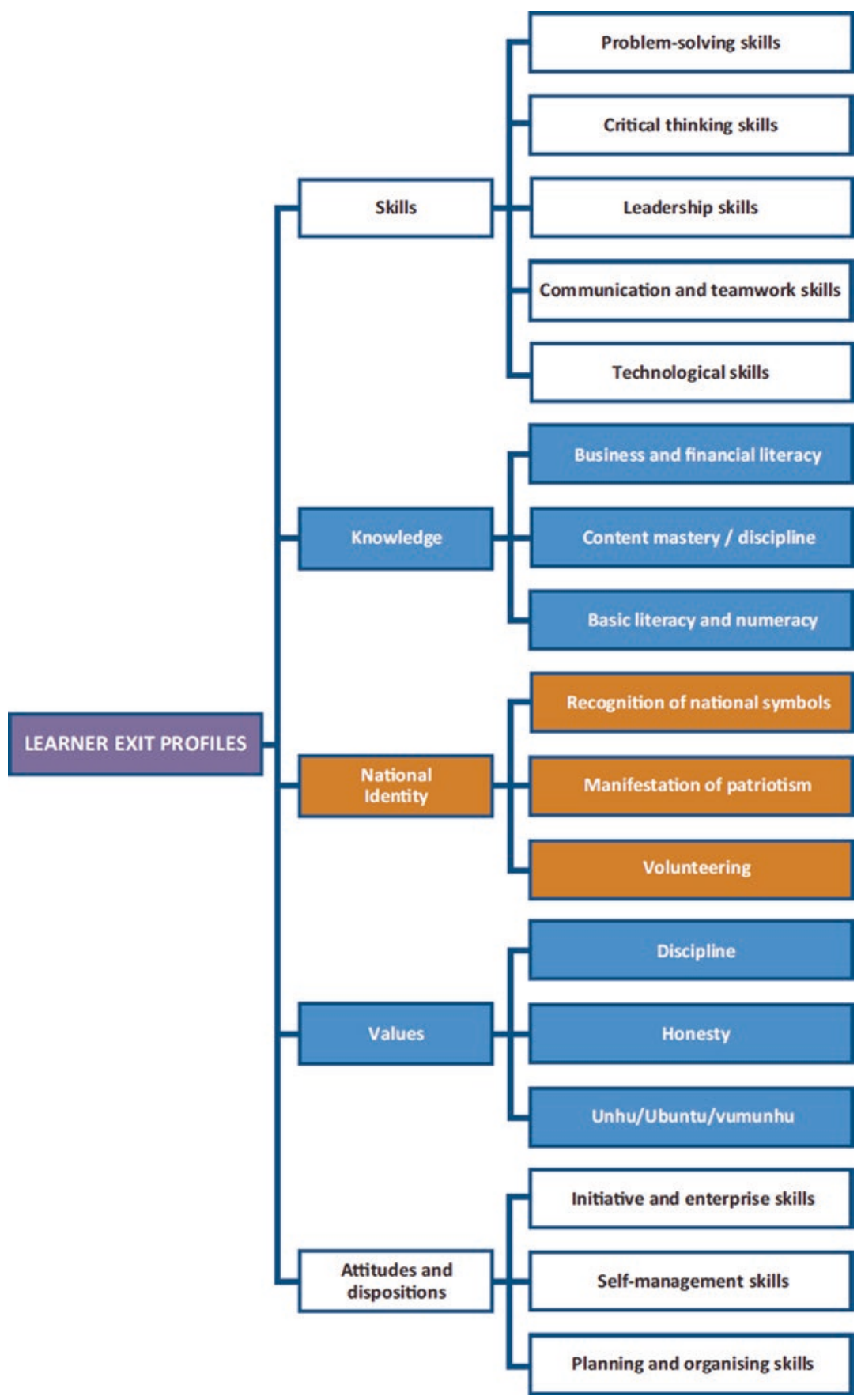

Fig. 7.5 Learner exit profiles

Source: Ministry of Primary and Secondary Education, Curriculum Framework Document (2015) 
In terms of preparation and availability of learning materials to support student learning, the CDTS team was involved with the tendering, publishing, and distribution of textbooks while vetting their quality from multiple local publishers to ensure they are aligned with the syllabus and curricular requirements. MoPSE even considered the use of additional learning materials such as science kits. ECG partners supported MoPSE in the procurement and distribution of textbooks and science kits.

Alongside this, CDTS used the principles of science of teaching to design the teacher professional development experience for equipping teachers in their new role of a facilitator. It not only developed the content for the syllabus interpretation workshops but also undertook workshops for all trainers at all levels from provincial to district for delivering grade-level national teacher training workshops. It also produced teacher guides to support teachers in planning and delivering classroom instruction, especially for new learning areas. The professional perspective in the following section covers these aspects in detail.

\subsubsection{Professional Perspective}

The professional perspective requires us to consider the core questions of "rules about who can teach, what qualifications they need to have, how and when they could be employed, how could they be trained and developed professionally to deliver their responsibilities" (Reimers, 2020, p. 16). Professional development sets a foundation for in-classroom pedagogy and acts as a driver for change. As Zimbabwe shifted from a content knowledge to a competency-based curriculum, it was essential that the role of teachers also shifted from a content deliverer to facilitator of learning. This shift was crucial for the success of the curriculum reform and eventually for Zimbabwe's economy to bear the fruits of the hard work.

The ministry acknowledged this need and invested in teacher professional development to maintain and ensure the quality of teaching and instruction. Zimbabwe's Curriculum Framework thus defined a set of principles that must guide teaching and learning, and redesigned the roles of teaching staff to align them to the new curriculum goals. One of its positive aspects was the focus on not just teachers but also school heads. ${ }^{?}$

The ministry rolled out several measures to bring its teaching force up to speed with the curriculum reform and to be able to effectively use teaching methods such as discovery, project-based, problem-based, and design-based.

This shift in expectations, attitudes, and behaviours of the teaching workforce was considerable and challenging. The preparation of teachers thus began with the launch of the Teacher Capacity Development Programme in 2014, which aimed at (a) upgrading teachers' educational qualifications to effectively contribute to the

\footnotetext{
${ }^{7} \mathrm{~A}$ table describing the new roles of teachers and school heads under the $\mathrm{CBC}$, as defined in the new curriculum framework is provided in Fig. 7.6.
} 


\begin{tabular}{|c|c|}
\hline The Teacher & The School Head \\
\hline $\begin{array}{l}\text { - Uses a wide range of methods adapted to the } \\
\text { learner's situation and needs in the context of } \\
\text { interactive pedagogies } \\
\text { - Reinforces connections between learning } \\
\text { areas and disciplines and promotes integrated } \\
\text { learning } \\
\text { - Is able to integrate cross-cutting issues, such } \\
\text { liberation history as part of the struggle for } \\
\text { human rights and education for participatory } \\
\text { citizenship; peace education; education for } \\
\text { sustainable development; gender equality } \\
\text { - Possesses intercultural understanding; life } \\
\text { skills; health education; economic and } \\
\text { entrepreneurial education; media education; } \\
\text { ICT and e-learning } \\
\text { - Is interested and participates in the } \\
\text { development of customized curricula and } \\
\text { learning materials, as well as the establishment } \\
\text { of flexible plans of study in compliance with } \\
\text { the school autonomy principle } \\
\text { - Possesses the capacity to identify learning } \\
\text { problems and provide appropriate support } \\
\text { - Is interested in progress and formative } \\
\text { assessment with a view to providing guidance, } \\
\text { counselling, motivation and support to } \\
\text { learners } \\
\text { - Communicates and integrates well with } \\
\text { learners, parents and other stakeholders } \\
\text { - Facilitates learning for learners and engages } \\
\text { them in meaningful activities } \\
\text { - Is interested and able to engage in teamwork } \\
\text { and participates in communities of practice. }\end{array}$ & $\begin{array}{l}\text { - Provides a learner-friendly, safe, pleasant and } \\
\text { enabling learning environment } \\
\text { - Involves stakeholders and education partners } \\
\text { in school decisions } \\
\text { - Provides for differentiated learning and } \\
\text { choice in the context of a broad curriculum } \\
\text { - Monitors continuous assessment and learner } \\
\text { profiles } \\
\text { - Provides for consistency across the school } \\
\text { ("whole-school approach") in promoting } \\
\text { learner-centred teaching in their establishment } \\
\text { - Engages in school networking to promote } \\
\text { exchanges on, and mutual learning from } \\
\text { effective practices of learner-centred teaching } \\
\text { and learning elsewhere } \\
\text { - Supports school-based teacher in-service } \\
\text { training and mentoring as a means to improve } \\
\text { the teaching skills of staff by combining } \\
\text { theoretical and practical aspects in real school } \\
\text { life situations } \\
\text { - Collaborates with stakeholders in crafting } \\
\text { school vision and mission and strategies in sync } \\
\text { with the Ministry direction. } \\
\text { - Works in collaboration with stakeholders in } \\
\text { designing a school development plan and } \\
\text { accountability procedures during } \\
\text { implementation } \\
\text { - Pay special attention to implementing the } \\
\text { principles and practices of inclusive education } \\
\text { by taking into account and addressing diversity } \\
\text { and the different learners' needs. }\end{array}$ \\
\hline
\end{tabular}

Fig. 7.6 New roles of teaching staff

Source: Ministry of Primary and Secondary Education, Zimbabwe Curriculum Framework (2015)

curriculum, and (b) addressing their technical and vocational training needs. Since then there have been continuous teacher capacity development efforts. At a high-level, the ministry focused on the dual approach of in-service training and teacher guides to equip its teachers in effective implementation of the new curriculum.

In Zimbabwe, in-service training comes under the purview of MoPSE. As per the ministry website (February, 2020) there are 127,091 teachers, Head of Departments, Deputy Heads, and Heads of school located in 8953 primary and secondary schools across Zimbabwe. The ministry planned for a phased training schedule, which was in-line with the phased curriculum roll-out. This meant that the teachers were trained a year before the curriculum was supposed to be rolled-out for their respective grades. This ensured all teachers were expected to be prepared before the 
curriculum roll-out (Fig. 7.4). Further details of the in-service training methodology have been covered under Sect. 7.4.2.

The second key component to equip teachers was the development and distribution of teacher guides to aid teachers in classroom instruction. It was believed that sharing of tangible resources such as reference documents would further benefit the teachers in the new curriculum implementation because they usually led independent classrooms without any external support or supervision. For effective classroom delivery, the ministry thus planned to publish teacher guides that would complement the pupil textbook. These are available for each learning area at grade level (infant, primary, and secondary), and cover topics ranging from syllabus interpretation, sample lesson plan, curriculum delivery, and assessment and evaluation to competency matrix. The guides are readily available on the ministry website and have hard copy versions to account for low internet penetration. While most of these materials have been distributed, there is evidence that some schools have been either missed out or have received insufficient quantities (Universalia, 2018).

Alongside in-service training and teacher guide publication, the ministry also focused on other essential teaching aspects such as (a) teacher recruitment to fill the vacancies, (b) reducing the pupil-teacher ratio (PTR) to increase classroom engagement, and (c) reassigning existing teachers who teach outside their areas of specialization, to teach in their areas of specialization. We do not have data on teacher recruitment and reassignment, but the PTR either stayed stagnant or increased between 2013 and 2017. At 12\%, the highest increase was observed in ECD ratio whereas the secondary ratio remained static (Universalia, 2019, p. 97). While this is not a positive development, it is alleviated by the fact that pupil to trained teacher ratios (PTTRs) declined across all levels during the same period. Again at $43 \%$ decline, ECD observed the biggest improvement, whereas both primary and secondary observed a modest decline.

\subsubsection{Institutional Perspective}

The Institutional perspective requires us to consider the core questions of "how the social and institutional structures supported teaching and learning, how various stakeholders interact with each other, and how their quality of educational delivery and reform implementation was monitored at various levels (Reimers, 2020)." In addition to this, the perspective also considers how the federal and local governments are coordinating with other stakeholders in not only ensuring the reform implementation but also monitoring its quality. In the Zimbabwean context, we try to analyze this through three lenses (a) Coordination between Stakeholders (b) Alignment of monetary funding and spending, and (c) Assessment reforms and insights. 
(a) Coordination between Stakeholders: The ZCF reform was not driven by the ministry alone, but rather involved several stakeholders. ECG is a crucial entity in this regard. It provides consultation and promotes dialogue between the government and its partners on the development of the education sector in Zimbabwe. The World Bank, UNICEF, UNESCO, and GPE contributed to the GPE Fund which supported the development of the new curriculum and the preparation of the Education Sector Strategic Plan (ESSP). Additionally, DFiD and KfW, a German state-owned development bank, contributed to the Education Development Fund (EDF) and additional educational programmes by funding CSO interventions. UNICEF is the grant agent for both these funds.

As seen earlier, the ministry also conducted nationwide consultations with nearly a million people during the development and finalization of the curriculum framework. Additionally, close to half a million people were consulted for gathering feedback and inputs about the ESSP development and implementation. The ECG met every 2 months after this, to discuss the progress of the ESSP development and formally approved the final ESSP in February 2016 to implement between 2016 and 2020 (Universalia, 2018). This was operationalized through the National (NOP), 9 Provincial (POPs), 72 District operational plans (DOPs), and through the individual school development plans (SDPs).

The curriculum reform was implemented at the provincial level under the mantle of the provincial education office and its director; at the district level by the District School Inspector (DSI) and the district level education officers; and at the school level by school heads. Any challenges in implementing the reform at the school level were flagged to be solved by the district level officers, and similarly for district level by the provincial education officers. Any major problems or delays in implementation were flagged at the national level and to the ECG members, and they were addressed by the ministry directly. The CSOs also were authorized to flag any field implementation issues at the provincial and district level at the bi-monthly ECG meetings.

(b) Alignment of monetary funding and spending: To receive the funding earmarked from the GPE fund, the ministry must first spend the amounts on completion of activities and milestones, and then raise a receipt for payment to GPE. It must submit regular updates on the achievements and progress made on completing the activities mentioned as part of the ESSP to ECG and GPE. Any major delay in completing activities or achieving milestones must be flagged to ECG and GPE for prompt payments from the GPE fund. GPE then audits the activities and the corresponding spend by matching them against the activities mentioned under the finalized ESSP, and only approves payments which strictly adhere to ESSP plans. Any activities which do not match the ESSP plans are rejected and must be financed from the ministry's annual budget. Once GPE approves the expenditure and reimbursement of the same, UNICEF which is the grant agent for the GPE fund, releases the payment to the ministry. This process ensures that the ministry sticks to the originally agreed upon activities under the 
ESSP and ministry's continued commitment to the reform year on year under the multi-stage multi-year ESSP. This also ensures that the ministry has to finance any spending which is not aligned to the ESSP or is rejected by GPE. This has resulted in a strong internal audit compliance mechanism by the ministry's internal finance team, which has to report any departure from agreement to the Ministry of Finance, which then holds the MoPSE accountable for such deviations and makes sure MoPSE falls back on its own resources raised through various provincial, district, and school level levies.

(c)Assessment reforms and insights: Sound educational assessments are critical to measuring school performance, which, in turn, is a key to helping policy-makers plan interventions for school-improvement efforts. These could measure a variety of aspects ranging from students' performance in a subject to teacher's content knowledge or teaching. Without these, governments might end up spending limited resources of time and money on something that is not working. They are thus also imperative to decide where the education budget should be allocated based on what is working or its potential to do so versus what is not. It is then no surprise that as part of the curriculum reform, the government proposed a 360 degree/rounded/holistic approach to assessments. This includes assessing students through continuous assessments of knowledge, skills, abilities, values, and traits. The assessment is additionally planned to be both formative and summative, assessing the students' abilities and competencies from infant to secondary levels. For example, students' grade at junior level will be determined by a mix of continuous assessments and performance on the national examination. At the "O" level, the grade will be based on theoretical, practical, and continuous assessment percentage (Universalia, 2019).

An assessment framework policy at Infant level has been drafted and is currently under review and finalization by MoPSE, Zimbabwe (Universalia, 2019). A new assessment framework for primary and secondary grades is also being drafted by MoPSE. Zimbabwe School Examination Council (ZIMSEC), a parastatal of the MoPSE, Zimbabwe is mandated with developing all the examinations in the schooling system and is currently working on developing and implementing the new continuous assessment framework and methodology. Based on this assessment framework, the formative and summative learning assessments, including the end of level examinations such as ZELA ${ }^{8}$, Grade 7, "O" Level, and "A" Level will be reformed to align with the new curriculum. There is also a possible move away from summative to continuous formative assessments coupled with practical year-end examinations (Universalia, 2018). The delays and implementation challenges of the assessment reforms have been covered in detail under 7.4.1.

\footnotetext{
${ }^{8}$ ZELA assessments are developed by the funding support of UNICEF, test development support of ZIMSEC and implementation by a sub-department "ZELA" team within the ministry; All other assessments are developed and administered by ZIMSEC.
} 


\subsection{Results and Challenges}

The results and challenges of the Zimbabwean curricular reform have been closely monitored by both GPE and UNICEF through their annual evaluation reports. These can be grouped under three broad categories (a) Infrastructure and Implementation,

(b) Teacher Capacity and, (c) Economic.

\subsubsection{Infrastructure and Implementation}

1. Curriculum Packets: 13,000 copies of Curricular CD packets containing soft copies of curriculum framework document, syllabi documents, teacher guides and assessment activities to be used by teacher were developed and delivered to all schools through district level distribution mechanisms

2. Syllabi development: 144 Syllabi were translated with support from GPE into 13 regional and 8 indigenous languages

3. Textbooks: Procurement and distribution of 4,090,763 textbooks to 5,441 primary schools completed

4. SIG grants: 6,057 schools received School Improvement Grants from UNICEF totaling around 12 Million USD

5. Science Kits: MoPSE and UNICEF procured 12,600 science kits for 4,377 primary schools - 2,100 supported by GPE, remainder supported by EDF; $100 \%$ of all secondary schools have been provided with science kits by UNICEF funds

6. ICT Labs: A total of 1,200 schools with computer labs were developed through the GPE grants from 2016 onwards

7. Assessment related results: ZELA assessment results in 2018 showed improvement in mean performance for mathematics $(2.3 \%)$ but remained about the same for reading (ZELA, 2018). UNICEF and EDF grants have ensured that Zimbabwe has participated in ZELA assessments every year from 2015 onwards. Similarly, the country has participated in the 2013 SEACMEQ regional assessments, whose results are awaited, and as of January 2020, the country is also in the midst of planning implementation of SEACMEQ 2020.

In terms of challenges, some stakeholders reported that implementation of the new curriculum had been rushed, and this had led to inadequate levels of learning materials of certain learning areas and poor provision of textbooks. While the ministry has developed syllabi for all learning areas from ECD to Form 6 level, there are still few learning areas for which textbooks are yet to be published after 2 years of the reform. These are primarily new learning areas and thus the teachers are facing difficulties in delivering these because of a lack of learning area specific pre-service or in-service training. This could be because MoPSE could not get private publishers to keep up with the demands and did not anticipate enough the timeline required to get the support and validation from CDTS to get the new textbooks approved. Further, procurement remains a challenge as the purchasing of textbooks is slow 
because of the bureaucratic processes involved and inadequate funding, so the textbook-student ratio is still inadequate, which prevents students from having their own material to study and practice their lessons (Universalia, 2019). Our focus groups with the teachers and school heads highlighted that at times, the textbookstudent ratio can be as low as 1:10 for core subjects and 1:50 for non-core subjects.

Second, while the CDTS has reviewed curriculum and syllabus for its alignment, quite a few teachers and parents also mentioned that the curriculum is not progressing at the right level. They felt that the content is heavy for early grades and there is not much to focus on for higher primary grades. As mentioned in Sect. 7.4.3, this could be because the curriculum had broad statements for each learning area, which had been synthesized at the end of school level, whereas the syllabus was more detailed and specifies the learning objectives by grades.

Third, it is important to note that the assessment framework has been delayed since the beginning of the ZCF implementation (2016) owing to capacity gaps within MoPSE and ZIMSEC. It should hopefully be implemented within the turn of this year (2020) or early next year considering the consultative process of engaging stakeholders for comments and revising the draft assessments framework before its finalization and approval. Until then, the continuous assessment methodology and tools for assessment are critically required reforms that are awaited on a priority basis across the Zimbabwean school system. This is critical because the teachers were only trained on interpretation of the new syllabi and not on how to assess students in a continuous manner. As a result, more than $95 \%$ of them are still resorting to assessing students using methods learnt while they were at teacher colleges training to be teachers - methods to assess students on their content knowledge and rote memorization rather than on demonstrable skills. Some of the assessment practices from the earlier systems of assessing students periodically - unit tests, monthly tests, end of year assessments - are still continuing but these again are reduced to knowledge based assessments based on the capacity and know-how of teachers.

Fourth, while ICT and practical training or labs are the engines of the ZCF, there are schools that do not have the relevant infrastructure - computer labs, science labs, or lab equipment. While some schools do have computer labs, there is no electricity to render computer benefits. Schools with electricity only receive it during the hours where the school is not in session. Even schools in urban areas complained of power outage and internet connectivity issues. Students, teachers, and parents thus are unable to access educational information for developing skills and competencies. Without these resources, the outcomes and results of the ZCF will be difficult to realize.

Lastly, promoting inclusivity has also been a challenge. Despite the fact that MoPSE involved a high number of stakeholders in this reform, the dialogue was mainly between structures at the national levels. At the sub-national level, there was a gap due to the dysfunctionality of district-level communities which lacked appropriate resources, direction, and capacity (Universalia, 2019). 


\subsubsection{Teacher Capacity}

In terms of professional capacity development, in 2016 alone, over 70,000 teachers who started implementing the curriculum in 2017, were trained. Further, as of early 2020, the ministry has claimed that all teachers teaching the new curriculum have been trained either directly or indirectly through a cascaded training model. This implies all teachers except for Grade 7 (curriculum roll-out planned for 2021) have been trained.

However, the in-service training primarily focused on syllabus interpretation rather than the methodology of teaching. The parts that focused on methodology were not learning area specific. This is crucial to note because several new learning areas were introduced as part of the reform, so it was essential to receive training focused on these, especially for primary grade teachers, who are required to teach all subjects in Zimbabwe. Second, this was a one-time annual training rather than an ongoing training support. Additionally, given the cascading model of in-service training, teachers are not fully satisfied with the frequency and content of the training. Though this model ensures effective resource distribution, ultimately it leads to loss of information as it trickles down the levels. As a result, teachers do not feel prepared to deliver the content. They desire for learning area specific pedagogical examples and action-oriented practical methods for delivering ZCF. This is especially true of primary grade teachers who have to teach all learning areas but are not trained to do so.

Additionally, while the government has undertaken several essential measures for the teaching workforce, it is worth noting that amidst the economic turmoil, the best Zimbabwean teachers likely moved out of the education system. Thus challenges have been noted in relation with the recruitment of teachers to ensure that the ministry is able to react to turnover and that students are not left without teachers as they are essential to learning. During our visit, ministry officials reported that the country does have a long waitlist of about 15-20 thousand teachers waiting to be recruited. All eligible teacher students are required to register into the ministry's database to be eligible for selection into the teaching workforce. The ministry then recruits the teachers higher up in the waitlist based on their province preference. There is no inclusion of a quality or a competency criteria.

\subsubsection{Economic}

In Zimbabwean Dollar (ZWD) terms, the MoPSE budget increased more than 40 times from 200 Million Dollars to 8 Billion in 2019-2020 due to hyperinflation and programming changes under the curriculum reform. MoPSE budget currently accounts for nearly $15 \%$ of the total government expenditure and $6 \%$ of GDP. Alongside, donor funding continues to play a significant role, allowing MoPSE to initiate and implement numerous key reforms to implement interventions 
to expand access or enhance quality. Donor funding through the Education Development Fund (EDF), the Global Partnership for Education (GPE), and other sources has amounted to close to USD 230 million between 2014 and 2020 (Universalia, 2019). Substantial resources from the NGO partners also support education. The ministry is currently consolidating different grant funding programmes into a single harmonized approach as a part of the school financing policy, which has been drafted and is under review by the ECG partners.

However, limited financial resources at the MoPSE level prevented the implementation from sticking to the initial schedule. This resulted in an excessive reliance on donor and parental funding for non-salary expenditures which is not a sustainable strategy in the long-run. Education affordability and sharp decline in teacher salaries was another hindrance.

Second, as of early 2020, MoHTESTD continues to train the new workforce using the old curriculum. On average, MoPSE has been spending close to 3 Million USD on professional capacity development, especially due to duplication of efforts by re-training new teachers who were originally trained on the previous curriculum. This can be optimized to some extent if the curriculum of the teacher education colleges is aligned with ZCF. Alignment with higher education would ensure continuity and consistency between the two and redirect the saved budget on other critical reform aspects.

Lastly, while limited internet connectivity has been highlighted as a challenge under infrastructure, it is also worth noting that a major deterrent is the installation costs and annual internet access charges. This cost is generally borne by schools from their school development funds collected through pooled-in resources from parents. Since the successful ZCF delivery depends heavily on fully functioning ICT labs in all schools across the countries, MoPSE needs to align with the Ministry of Information and Communications Technology (MoICT) to make access to stable and affordable, if not free, internet a reality for schools to realize the ICT benefits.

\subsection{Conclusion}

Amidst the political, economic, and financial challenges, MoPSE did its best by taking the courageous step of undertaking a full-fledged systemic overhaul and adjusting the plan as required. The ministry was driven with the mission of making schooling relevant for all Zimbabwean children and has moved a step closer to it. The Zimbabwean Curricular Reform is also ambitious in that it addresses the five perspectives of educational change proposed by Reimers (2020). While the reform is in its last leg, with the ZCF rolled out for Grade 6 in 2020 and plans for Grade 7 roll-out in 2021, there is much to appreciate and learn from the progress thus far. Even though we heard mixed reviews from several stakeholders, all the criticism was primarily targeted towards implementation and contextual situations such as economic hardships in terms of hyperinflation, economic stability, and sanctions from other countries and development partners, which were not in the ministry's 
control. This criticism is similar to educational reforms in other developing countries such as Kenya.

The ZCF implementation is expected to be completed in 2022 and the preparations for curriculum review will start in 2021. Hopefully, the curriculum review process will benefit from the findings of the Education Sector Analysis and incorporate these in the next phase of curriculum improvement and implementation (CBC V2.0) from 2022 to 2027. It remains to be seen whether Zimbabwe would be able to learn from the challenges faced in reform V1.0 and address all gaps in its curricular reform V2.0. The extensive support from the ECG, belief from the political cadre in the general direction of the reform, and the strong will to continue improving and implementing the reform are on its side. Thus, with improvements in economic conditions, international sanctions, and other associated hardships, Zimbabwe has the potential to once again be at the forefront of the educational achievement and progress in the continent.

\section{References}

Collaborative for Academic, Social, and Emotional Learning (CASEL). (2017). CASEL Wheel \& Competencies. https://casel.org/wp-content/uploads/2019/12/CASEL-Competencies.pdf.

Demographic and Health Survey. (2016). https://dhsprogram.com/pubs/pdf/FR322/FR322.pdf. Accessed February 5, 2020.

Education Encyclopedia. (n.d.). https://education.stateuniversity.com/pages/2099/InstructionalStrategies.html. Accessed June 3, 2020.

EMIS. (2017). Annual Statistical Digest. UNESCO Institute of Statistics. http://uis.unesco.org/ en/country/zw

ESSP. (2016). Education Sector Strategic Plan. Ministry of Primary and Secondary Education, Zimbabwe.

In-Country Research. (2020). Conducted by Jayanti Bhatia and Venkatesh Reddy Mallapu Reddy. Interviews were conducted with 52 officials from 6 departments of MoPSE - Curriculum Development and Technical Services Department; Human Resources and Discipline Department; Primary, Secondary and Non-Formal Education Department; Procurement Management and Business Development Unit; Centre of Education, Research, Innovation and Development; Finance Department.

Kageler, S. (2015). Education Sector Analysis (ESA). Ministry of Primary and Secondary Education, Zimbabwe

Narrative Report. (2014). Narrative Report (2014-2015). Curriculum Review Process. Zimbabwe, Ministry of Primary and Secondary Education

Zimbabwe School Examinations Council (ZIMSEC); Zimbabwe Early Learning Assessments Team (ZELA); South East African Council for Monitoring Educational Quality (SEACMEQ).

Education Coordination Group partners such as World Bank, UNICEF, UNESCO, CSOs

Textbook Publishers.

Provincial Education Directors, District School Inspectors, National Association of Primary School Heads and, National Association of Secondary School Heads.

Additionally, we held individual and focus group interviews in 7 schools in 3 out of 9 provinces in Zimbabwe where we interviewed 32 School Heads, 70 Teachers, 36 Parents and 38 Students.

Reimers, F. (Ed.). (2020). Educating students to improve the world. Singapore: Springer.

UNESCO. (2017). Zimbabwe demographics. http://uis.unesco.org/country/ZW. Accessed June $6,2020$. 
UNICEF. (2009). https://www.unicef.org/media/media_47915.html. Accessed June 3, 2020.

Universalia. (2018). Aslam, M., Rawal, S., \& Outhred, R. (2018). GPE 2020 Country-level prospective evaluations. Zimbabwe first annual report.

Universalia. (2019). Aslam, M., Rawal, S., \& Turner, F. (2019). Prospective evaluation of GPE's country-level support to education. Zimbabwe second annual report.

World Bank. (2014). Literacy rate, adult total (\% of people ages 15 and above). Zimbabwe: World Bank. https://data.worldbank.org/indicator/SE.ADT.LITR.ZS?locations=ZW. Accessed February 5, 2020.

ZELA. (2018). An evaluation report of the 2018 Zimbabwe Early Learning Assessment (ZELA) cycle. Report to the Ministry of Primary and Secondary Education from ZIMSEC and UNICEF.

ZimASSET, G. o. (2015). Zimbabwe agenda for sustainable socio-economic transformation (ZIM ASSET): Towards an empowered society and a growing economy, October 2013-December 2018. (2015). Harare: Government of Zimbabwe.

Zimbabwe Curriculum Framework. (2015). Curriculum framework for primary and secondary education report (2015-2022). Zimbabwe, Ministry of Primary and Secondary Education.

Djénéba Gory is a French-Malian Master's in Public Administration graduate at the Kennedy School of Government at Harvard University. She started her career as a financial auditor based in Paris for 4 years. She moved to Cote d'Ivoire where she focused on humanitarian and development projects. She provided audit/advisory services to non-profits in more than 15 African countries (ie. Burkina Faso, Central African Republic, Djibouti, Nigeria, etc) for 3 years. More recently, she moved to Switzerland where she worked on humanitarian projects implemented worldwide. At Harvard, she focuses her studies on education policies, gender and women's empowerment. She is the co-founder of the Suadela which is a nonprofit organization whose mission is to increase WestAfrican teenage girls' power by building their negotiation skills.

Jayanti Bhatia is a 2020 Ed.M. International Education Policy graduate from the Harvard Graduate School of Education. She believes that Social and Emotional Learning should be embedded within the mainstream curriculum to drive learning and life readiness for all children. After completing her Bachelor's in Physics Honors from Hindu College, Delhi University, Jayanti joined $\mathrm{ZS}$, a consulting and professional services firm in 2012. Yet one cause that has always stayed close to her heart is quality education for all. Her self-fueled passion has driven her to lead many initiatives for children in slums, learning centers for migrants, and low-cost private schools across India (2011-Present). Consulting at the same time has empowered her to use her skills interchangeably, and simultaneously see the bigger picture and intricacies of ground projects. She is now looking forward to leveraging her professional skills in the domain of education to ensure the holistic development of all children.

Venkatesh Reddy Mallapu Reddy has more than 10 years of experience in the Indian education sector in both for-profit and not-for-profit organizations in Strategic Partnerships and Development, Project Management, Financials and Budgeting, Monitoring \& Evaluation and Communications roles. Most recently, he was the Strategic Partnerships \& Management Lead for 4 years with his last employer, handling all the strategic engagements with education ministries and senior government officials, international agencies and foundations like World Bank, UNICEF, UNESCO, USAID, MSDF, MacArthur, and partner CSO/NGOs. He has worked with education systems and stakeholders in India, Bhutan, Afghanistan, Maldives, Thailand, United States and Zimbabwe. He has managed multiple large-scale diagnostic student assessments ( $>30 \mathrm{~K}$ Students data collected) projects in India and helped collect more than 1.5 Million students learning outcomes data and interviewed more than 10,000 teachers and school heads. He is interested in using low-stakes diagnostic assessment data and student/teacher/school background data to improve service delivery by making education more personalized and targeted to individual stakeholders (for ex: 
personalized learning and addressing of learning gapsistudent misconceptions, targeted teacher training programmes which address individualized needs of teachers) and help implement better policies and decision making at all levels and levers in the system.

$\mathrm{He}$ is a graduate of the Master's Program in International Education Policy at the Harvard Graduate School of Education and has a passion for Comparative Policy Research and Analysis in International Education, Assessments based insights and reforms, Social-Emotional Learning and Early Childhood Education.

Open Access This chapter is licensed under the terms of the Creative Commons Attribution 4.0 International License (http://creativecommons.org/licenses/by/4.0/), which permits use, sharing, adaptation, distribution and reproduction in any medium or format, as long as you give appropriate credit to the original author(s) and the source, provide a link to the Creative Commons license and indicate if changes were made.

The images or other third party material in this chapter are included in the chapter's Creative Commons license, unless indicated otherwise in a credit line to the material. If material is not included in the chapter's Creative Commons license and your intended use is not permitted by statutory regulation or exceeds the permitted use, you will need to obtain permission directly from the copyright holder.

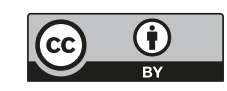

